\title{
EFFECTS OF SOME NARCOTIC ANALGESICS UPON THE MONOSYNAPTIC REFLEX INHIBITION FROM MUSCULAR AND CUTANEOUS AFFERENTS IN SPINAL CORD OF THE CAT
}

\author{
Nobuyoshi IWATA and Yutaka SAKAI \\ Medical Lahoratory for Pharmacology, Central Research Laboratoric's, \\ Sankyo Co., Ltd., Shinagawa-ku, Tokyo
}

Received for publication Novenber 20, 1970

It has been know that, at a small dose, narcotic analgesics depress polysynaptic reflex activity in the spinal cats (1) and nociceptive reflexes in the spinal rats (2), as well as in spinal cats and dogs ( 36 ), where they do not depress, or slightly enhace the monosynaptic reflex (3). In order to explain this depression induced by narcotic analgesies, it has been suggested that the interneurons responsible for mediation of the polysynaptic reflex are suppressed (3). Further, for a remarkable depression of nociceptive reflex discharges from high threshold cutaneous afferents by morphine and pethidine, it has been suggested that some interneurons activated by such small fibers of the cutaneous nerve might be inhibited (7). On the other hand, large doses of morphine $(15.20 \mathrm{mg} / \mathrm{kg})$ has been reported to potentiate the Group la inhibition and depress the recurrent inhibition via Renshaw cell arcs in decerebrate cats (8).

However, it remains still unknown whether narcotic analgesics may depress spinal interneurons generally or special interneurons specifically. Therefore, it was attempted in the present study to find either one of these. As a test system, the effects of some narcotic analgesies upon the inhibitory influences 10 the extensor monosynaptic reflex from flexor reflex alferents were studied using unanesthetized low spinal cats.

\section{MFTHODS}

Twenty-four adult cats were used. All surgical operalions were performed under ether anesthesia. After tracheal cannulation, the spinal cord was transected beiween $\mathbf{T}_{13}$ and LI during local anesthesia with $1 \%$ procaine, then the lumbosacral spinal cord was exposed from $L_{4}$ to $S_{2}$. After cutting the ventral roots from $L_{i i}$ to $S_{1}$, that of $L_{7}$ or occasionally Si was placed on the platinum wire clectrode, and mono- and polysynaptic reflexes evoked by stimulating the peripheral nerves were recorded from this root. The responses were projected on the cathode-ray oscilloscope (Tektronix 565).

For stimulation, collar-type electrodes were placed to the following nerves of the ipsilateral hindlimb; medial gastrocnemius-soleus, quadriceps, sural, biceps-semitendinosis (BST) and fexor digitorum longus (FDL). In addition, two pairs of the similar electrodes were placed to the saphenous nerve for stimulating at proximal and for recording 
at distal point. Electrical shock $(0.01-0.1$ msec, $0.3-0.5 \mathrm{~Hz})$ was applied to these nerves from an electronic stimulator (MSE-40, Nihon Kohden).

The incoming volleys elicited by the conditioning stimulation of muscle nerves were monitored with a Ag-ball electrode placed on the adequate dorsal root entry zone. The testing monosynaptic reflexes were superimposed on a single frame at various intervals after the conditioning stimulation.

The dorsal root potentials from the quadriceps and saphenous nerves were recorded from $L_{7}$ or $S_{1}$ dorsal root filaments placed on a platinum wire electrode and cord dorsum potentials from these nerves were also recorded with Ag-ball electrode placed on the adequate dorsal root entry zone. These two potentials were projected on a cathode-ray oscilloscope through a preamplifier with a time constant of 0.3 second.

The exposed spinal cord was covered with warmed mineral oil and the temperature of both spinal pool and rectum were maintained between $37-39$ C with a thermoregulating device made in our laboratory. Polyethylene catheters were inserted to the contralateral femoral vein for drug administration and femoral artery for monitoring the blood pressure. As soon as surgical operations were completed, ether anesthesia was discontinued and the animal was immobilized with gallamine triethiodide (Gallamine, Teikoku Chemical Industries) and artificially respired (30; min). Experiment was started at least 3-4 hours after discontinuing the anesthesia.

The drugs used in this report were as follows; morphine hydrochloride (Sankyo), fentanyl citrate ( $\mathrm{N}$-(1-phenethyl-4-piperidinyl) propionanilide dihydrogen citrate, Jansen Pharmaceutical Co.), oxymorphone (Sankyo), dimethylthiambutene (Ohton, Ono Pharmaceutical Co.) and nalorphine (Sankyo). Drugs were dissolved in physiological saline and diluted to $1 \%$ (morphine, dimethylthiambutene, oxymorphone and nalorphine) and $0.008 \%$ (fentanyl) in each and were administered intruvenously slowly so as not to induce the blood pressure fall.

\section{RESULTS}

Effects of fentanyl and morphine upon the cutaneous inhibition of the extensor monosynaptic reftex

As was previously known (11) and shown in Figs. 1 and 2, the monosynaptic reflex (MSR) evoked by the stimulation of the medial gastrocnemius-soleus nerve (mG-S-MSR) was inhibited by the preceding conditioning shock to either the saphenous or sural nerve at a supramaximal intensity (cutaneous inhibition). This inhibition began about 5 msec after the shock, attained the maximum at about $10-15 \mathrm{msec}$ and gradually decayed. It took about 30-40 msec until the complete recovery (Fig. 1A, C). When either fentanyl, a potent narcotic analgesic $(9,10)(40 / \mathrm{gg} / \mathrm{kg}$, Fig. 1B), or morphine (3 mg/kg, Fig. 1D) was administered intravenously, the duration of the cutaneous inhibition was shortened from about $25 \mathrm{msec}$ to about $15 \mathrm{msec}$. However the onset latency and its peak time were almost uninfluenced. In most cases the rebound facilitation appeared after the cutancous inhibition (Fig. 1B), the MSR often being twice as large as the control. 
A

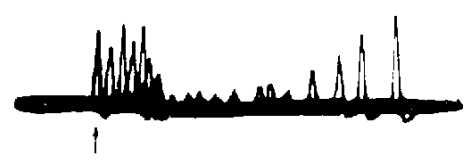

B

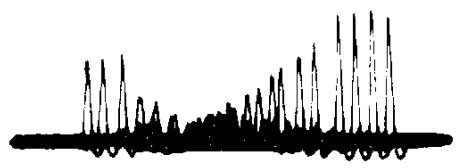

C

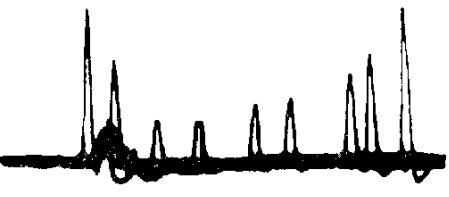

D

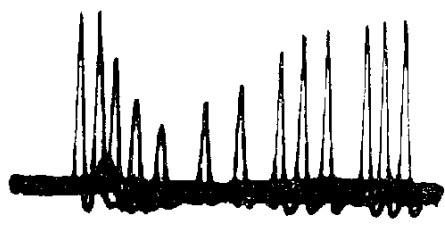

FiG. 1. Effects of fentanyl and morphine upon the cutaneous inhibition.

Monosynaptic reflex of the $\mathrm{L}_{7}$ ventral root was evoked from the medial gastrocnemius-soleus nerve $(0.01-0.1 \mathrm{msec}, 10 \mathrm{~V})$ at various intervals after the conditioning shock to the saphenous nerve at a supramaximal intensity for high threshold cutaneous afferents $(0.1 \mathrm{msec}, 50 \mathrm{~V})$. A and $\mathrm{C}$ represent the control state for the B and D, respectively. B : 5 minutes after fentanyl administration $(40 \mu \mathrm{g} / \mathrm{kg}), \mathrm{D}: 5$ minutes after morphine injection $(3 \mathrm{mg} / \mathrm{kg})$. Arrow in A indicates a timing of the cutaneous nerve shock. Time, $10 \mathrm{msec}$.

The elfect of fentanyl $(40 \mathrm{~kg} / \mathrm{kg}$ ) disappeared in $40-60$ minutes after administration (see below). When the same amount of fentanyl was injected after the conplete recovery, the blockade of the late phase of the cutaneous inhibition was again observed with a similar time course and potency as with the previous injection. Thus, it is clear that the late phase of the cutaneous inhibition is depressed reversibly by a small dose of fentanyl and therefore it is considered that there is little, if any, tachyphylaxis upon repeated administration of fentanyl.

These effects were confirmed without exception in 29 trials in 13 cats with fentanyl (12 trials with $80 \mu \mathrm{g} / \mathrm{kg}, 10$ trials with $40 \mu \mathrm{gg} / \mathrm{kg}, 3$ trials with $20 \mu \mathrm{g} / \mathrm{kg}, 2$ trials with $8 \mathrm{qg} / \mathrm{kg}$ and 2 trials with $0.8 \mathrm{rg} / \mathrm{kg}$ ) and 21 trials in 21 cals with morphine (one trial with $10 \mathrm{mg} / \mathrm{kg}$. 5 trials with $5 \mathrm{mg} / \mathrm{kg}, 11$ trials with $3 \mathrm{mg} / \mathrm{kg}, 2$ trials with $1 \mathrm{mg} / \mathrm{kg}$ and 2 trials with $0.5 \mathrm{mg} /$ $\mathrm{kg})$.

As already known, this inhibition is evoked from low and high threshold afferents of cutaneous nerves, presumably from fibers of Group $\mathrm{A} \alpha$ and $\mathrm{A} \delta$ range (11-13).

Fig. $2 \mathrm{~A}$ shows the time course of the cutaneous inhibition when the saphenous nerve was stimulated at a supramaximal intensity for the high threshold fibers, together with two components of the nerve potential ( $A \Omega$ and $\Lambda i$ ) recorded from the distal end (Fig. $2 A$, insetted figure) (13). The onset latency of the first component of the nerve potential was about $0.3 \mathrm{msec}$ and that of the second was about $1.0 \mathrm{msec}$. Since the distance from the stimulating electrode (cathode) to the recording one was about $20 \mathrm{~mm}$, the calculated values for the conduction velocity of these fibers were about 60 and $20 \mathrm{~m} / \mathrm{sec}$, respectively. 
In order to determine the nerve component concerned in the cutancous inhibition, MSRs at $12 \mathrm{msec}$ (B) and $20 \mathrm{msec}$ (C) after a conditioning shock of varied intensity were plotted in Fig. 2B and C, respectively, against the shock intensity together with the nerve potential size. The $A \alpha$ potential reached its maximum at an intensity of about 2 times and $\mathrm{A} \delta$ component appeared at an intensity of about 1.8 times and reached maximum at about 2.5 times the threshold for Ace fibers (Fig. 2B, C). As shown in Fig. 2B, the mGS-MSR at $12 \mathrm{msec}$ after conditioning stimulus started to be depressed at near threshold intensity and depression became maximum at 1.5 times of the threshold. Whereas in
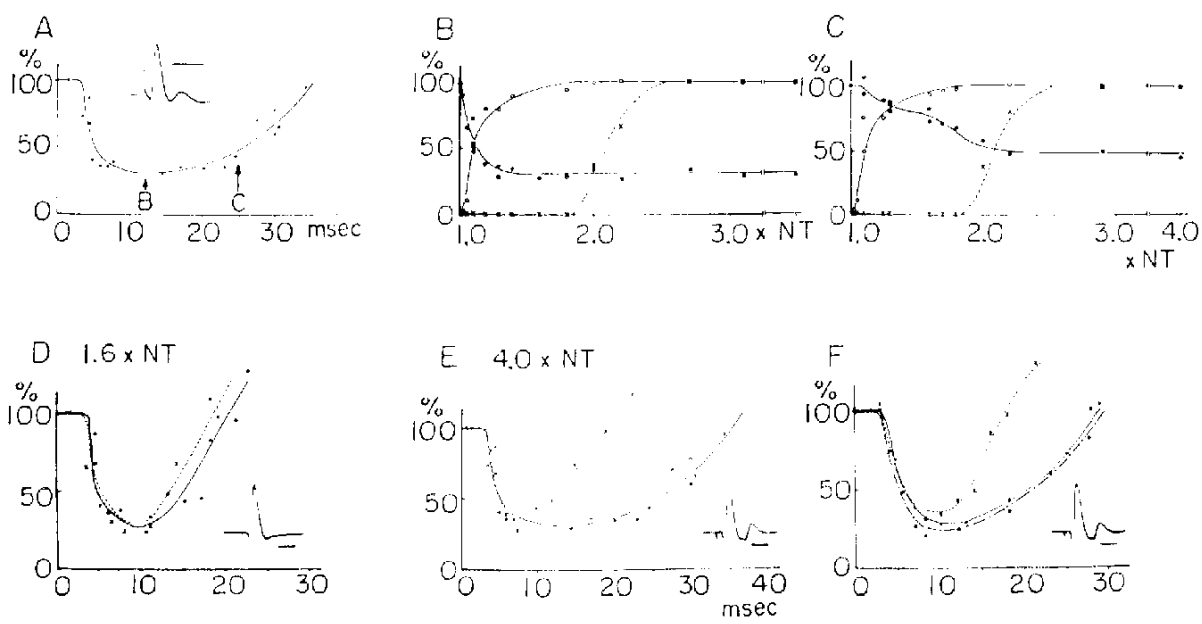

FIG. 2. Cutaneous inhibition sensitive to fentanyl and morphine.

Reflex discharges were recorded from $L$, ventral root, and the nerve potentials of the saphenous nerve were recorded from distal point. A : time course of the cutaneous inhibition evoked by shock given to the saphenous nerve at a supramaximal intensity for the A fibers. Abscissa in this graph and those in D, E and F represent the time in msec between testing and conditioning shocks and ordinates the size of the monosynaptic reflex, taking the control state as $100 \%$. B and $\mathbf{C}$ : amplitude of nerve potentials of fast $\mathrm{A} x$ (open circles) and slow Aó components (crosses) of the saphenous nerve and the sizes of the monosynaptic rellex for the medial gastrocnemius-soleus nerve (filled circles) were plotted against the conditioning cutaneous shock intensity in multiples of nerve threshold of A $\alpha$ fibers. MSR responses in $\mathrm{B}$ were evoked at testing-conditioning intervals of $12 \mathrm{msec}$ and those in $\mathrm{C}$ were at 20 msec. These tinings are represented by arrows with letters $\mathrm{B}$ and $\mathrm{C}$ in Fig. A. D : time course of the cutaneous inhibition, evoked at a low intensity shock (1.6 times of the nerve threshold activating A $\alpha$ component as indicated insetted potential) in the control state (open circles) and 7 minutes after fentanyl (40/g/kg, crosses). Note that the time course of depression for these two states are similar. E : same as in $\mathrm{D}$ but evoked by a stronger conditioning shock (4.0 times of the nerve threshold activating both $\mathrm{A} \alpha$ and $\mathrm{A} O \mathrm{f}$ fibers as indicated in insetted nerve potentials). Note that the time course became markedly shorter after the drug administration. F : effect of morphine and nalorphine on the time course of cutancous inhibition due to strong stimulation of the saphenous nerve. Open circles indicate control state before drug administration, crosses, 5 minutes after morphine $(1 \mathrm{mg} / \mathrm{kg})$ and filled circles, 3 minutes after nalorphine $(0.5 \mathrm{mg} / \mathrm{kg})$ given at the top of morphine effect (about 5 minutes after morphine). Time, $1 \mathrm{msec}$ for insetts of $\mathrm{A}, \mathrm{D}, \mathrm{E}$ and $\mathrm{F}$. 
$\mathrm{C}$, the inhibition observed at $20 \mathrm{msec}$ after conditioning stimulus developed not smoothly but with a break at about 1.7 times of the threshold. The MSR inhibition was about $20 \%$ up to this point, and then developed more, reaching a plateau level at about 2.3 times of the threshold. This breaking point roughly corresponded to the threshold intensity for the Ao elevation, and the sccondary increase of the inhibition paralleled with the development of Ad elevation of nerve action potential. Thus, it is clear that the MSR depression is induced by both $\mathrm{A} \alpha$ and $\mathrm{A} i \mathrm{i}$ components of the cutaneous fibers and further the later part of the depression is produced when the shock intensity is more than 2 times of the nerve threshold, presumably by Ao fibers.

In Fig. 2D and E, drug effects upon the cutaneous inhibition were compared at a low (1.6 times of $\mathrm{A} \alpha$ threshold) and a high (4.0 times of A $\alpha$ threshold, supramaximal intensity for Aò fibers) conditioning shock intensities. In the control with a low intensity conditioning shock the cutaneous inhibition was observed from about $5 \mathrm{msec}$ to $20 \mathrm{msec}$ after the conditioning and followed by a rebound facilitation (Fig. 2D, open circles), while with a high intensity one, the culaneous inhibition was prolonged to about $35 \mathrm{msec}$ as shown in $\mathrm{A}$ and $\mathrm{E}$ (open circles). After administration of fentanyl $(40 \mu \mathrm{g} / \mathrm{kg})$, the time course of the cutaneous inhibition at a weak conditioning stimulation was little affected (Fig. $2 D$, crosses), whereas that at a supramaximal intensity was markedly shortened from about $30 \mathrm{msec}$ to $15 \mathrm{msec}$ in duration (Fig. 2E, crosses). It is noteworthy that the remaining inhibition after fentanyl is almost the same regardless of the intensity of the conditioning stimulation of the saphenous nerve, and followed by a rebound facilitation.

Morphine showed similar effects. As illustrated in Fig. $2 \mathrm{~F}$ in another preparation, a small dose $(1.0 \mathrm{mg} / \mathrm{kg})$ of morphine blocked the late phase of the cutaneous inhibition and the total duration was shortened from about $25 \mathrm{msec}$ to $15 \mathrm{msec}$, and the rebound facilitation appeared.

This morphine effect--shortening of the total duration of the MSR depressionwas immediately abolished by nalorphine $(0.5 \mathrm{mg} / \mathrm{kg}$, filled circles).

In some cases, the MSR was also recorded from $S_{1}$ ventral root. The time courses of the cutaneous inhibition in this ventral root with low and high conditioning shock were similar to those recorded in $L_{\tau}$. A large dose of fentanyl $(80, \mu \mathrm{g} / \mathrm{kg})$ often blocked not only the late phase but also the carly phase of the cutancous inhibition recorded in $\mathrm{S}_{1}$ ventral root, in contrast to the selective block of the late phase in $\mathrm{L}_{\bar{\gamma}}$. However, relatively small doses of fentanyl (less than $40 \mu \mathrm{g} / \mathrm{kg}$ ) and morphine (less than $10 \mathrm{mg} / \mathrm{kg}$ ) blocked the late phase of the cutaneous inhibition selectively in this root as well.

\section{Time courses of fentanyl effect at various doses upon the cutaneous inhibition}

Time courses of the effect of fentanyl at various doses upon the cutaneous inhibition were studied. Testing and conditioning shocks were given at a fixed interval of $15 \mathrm{msec}$. In Fig. 3, three different doses, 40,8 and $0.8 / 1 \mathrm{~g} / \mathrm{kg}$, were sequentially administered in a spinal cat. The second and the third injection of fentanyl were applied after the complete recovery of the cutancous inhibition, i.e., 2 hours and one hour respectively after the previous injection. In control, the cutancous inhibition was about $65 \%$. Forty $\mu \mathrm{g} / \mathrm{kg}$ 


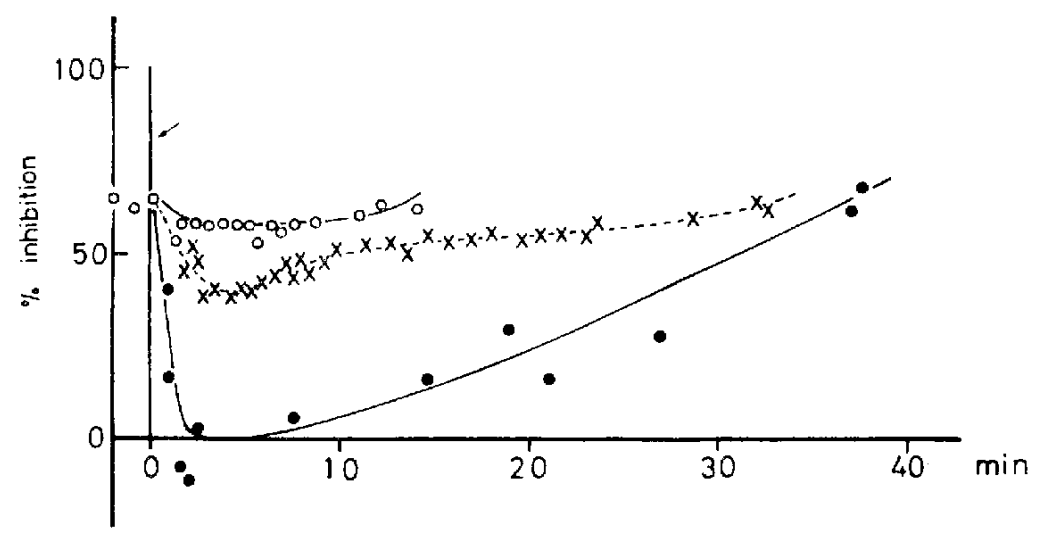

FIG. 3. Dose-response relationship of fentanyl effect on the cutaneous inhibition. Fentanyl was injected sequentially at different doses in the same preparation, $40(0), 8(x)$ and $0.8, \mathrm{~g} / \mathrm{kg}(6)$. Interval between conditioning and testing shocks was fixed at $15 \mathrm{mscc}$ (both stimuli being supramaximal) and the MSR inhibition is presented as percentage, taking the size without conditioning shock to the saphenous nerve as control. At least 1 hour was allowed to elapse between trials. Note that with the highest dose, the inhibition was completely abolished and a moderate facilitation appeared.

of fentanyl began to depress the cutancous inhibition immediately after the administration and blocked it completely in less than one minute. The MSR was rather enhanced (two filled circles under abscissa of Fig. 3) by the conditioning stimulation between 1.5 minutes and 8 minutes after administration. Thereafter, this fentanyl effect gradually decayed and the inhibition recovered in about 40 minutes (filled circles). When a dose of $8 \mathrm{\mu g} / \mathrm{kg}$ was administered about 2 hours later, the cutancous inhibition was supressed, though weak, with a similar time course. Peak of the fentanyl eflect was seen at about 5 minutes after administration. One hour later, $0.8 \mu \mathrm{g} / \mathrm{kg}$ was injected. The depression was slight, as much as about $7 \%$ (open circles).

\section{Effects upon the MSR inhibitions from other afferent inputs}

A. Group Ia and Ib inhibition: The Group la inhibition of BST-MSR by the conditioning stimulation of the quadriceps nerve was examined at an intensity less than 2 times of the nerve threshold. In accordance with the literalure (14), the onset latency, peak time and duration of this inhibition were about 2, 3 and $1.5 \mathrm{msec}$, respectively. This inhibition was followed by MSR facilitation which is considered to be due to Group Ib afferent fibers (15). To these imhibition and facilitation of the MSRs, neither morphine (3 $\mathrm{mg} / \mathrm{kg})$ nor fentanyl $(40 \mu \mathrm{g} / \mathrm{kg}$ ) induced any visible change.

When the quadriceps nerve was stimulated at an intensity 1.15 times the nerve threshold, the mG-S-MSRs were inhibited over a period from about $0.7 \mathrm{msec}$ to $35 \mathrm{mscc}$, with the maximal inhibition at about $8 \mathrm{msec}$ after the peak of the nerve potential evoked by the conditioning stimulation and recorded at the dorsal root entry. This inhibition of mG-S-MSR is considered primarily due to the Group Ib and II afferent fibers (15). Another Group Ib inhibition of MG-S-MSR was obtained by the conditioning stimulation 
of FDL nerve at an intensity less than 2 times the nerve threshold (15). As shown in Fig. $4 \mathrm{G}$ for the quadriceps nerve stimulation, neither fentanyl (40/ $/ \mathrm{g} / \mathrm{kg}$, filled circles) nor morphine ( $5 \mathrm{mg} / \mathrm{kg}$, crosses) caused significant effect on these Ib and If inhibitions. This was confirmed in 6 trials with quadriceps nerve stimulation and 7 trials with FDL nerve stimulation.

B. High threshold muscle afferents: When the quadriceps nerve was conditioned at supramaximal intensity, the mG-S-MSR was inhibited over a period from about $5 \mathrm{msec}$ to more than $50 \mathrm{msec}$ with a marked inhibition between about $7 \mathrm{msce}$ and $30 \mathrm{msec}$ (Fig. 4A). Effects of fentanyl and morphine were investigated in 15 cats. Although fentanyl $(40 \mathrm{~kg} / \mathrm{kg})$ did not induce any change in the latency and the maximal inhibition of the MSR ( $40 \%$ of control in amplitude), it shortened the duration of the inhibition remarkably to about $25 \mathrm{msec}$, the maximal inhibition being between 7 and $20 \mathrm{msec}$ (Fig. 4B). This effect disappeared almost completely in about 40 minutes after administration (Fig. 4C). One hour later, after taking the control record shown in Fig. 4D, $3 \mathrm{mg} / \mathrm{kg}$ of morphine was administered. Reduction of the duration of the depression was similarly obtained (E), which was antagonized by nalorphine $(0.5 \mathrm{mg} / \mathrm{kg}, \mathrm{F})$.

C. Recurent imhibition: The $\mathrm{mG}-\mathrm{S}-\mathrm{MSR}$ s recorded in split half of $\mathrm{L}_{7}$ ventral root were inhibited immediately after the conditioning shock of the another split half of the

A

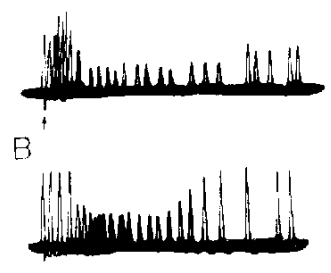

C

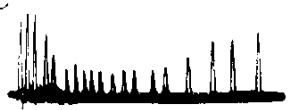

D

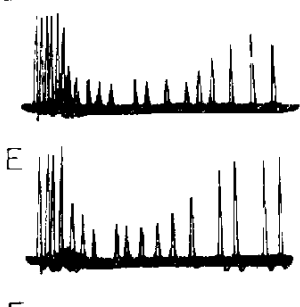

F

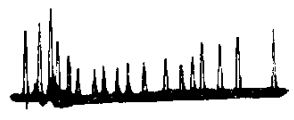

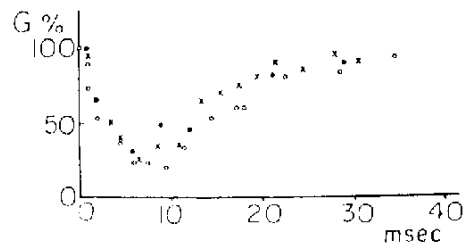

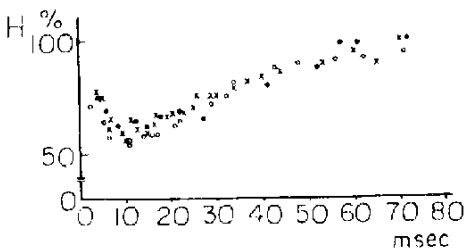

FIG. 4. Effects of fentanyl and morphine upon the inhibitory pathways from Group $\mathrm{Ib}$, Renshaw and high threshold muscle afferents to the medial gastrocnemius-soleus monosynaptic reflex.

Quadriceps nerve was stimulated for a conditioning at supramaximal intensity (A-F) and at an intensity 1.15 times the nerve threshold (G). $\mathrm{H}$ : split half of the $\mathrm{L}_{7}$ ventral root was conditioned and the MSR evoked by the medial gastrocnemiussoleus nerve shock was recorded from the other half of split $L_{i}$ ventral root. A-C depict effect of fentanyl and D-F that of morphine. A and D : control, B : 2 minutes after fentanyl $(40 \mu \mathrm{g} / \mathrm{kg})$. C : 60 minutes after fentanyl $(40 \mu \mathrm{g} / \mathrm{kg})$ administration. E : 3 minutes after morphine ( $3 \mathrm{mg} / \mathrm{kg}$ ), F : 2 minutes after nalorphine $(0.5 \mathrm{mg} / \mathrm{kg}$ ) given at the top of morphine effect, about 10 minutes after morphine. Note the restoration of prolonged inhibition in $C$ and $F$. Time, $10 \mathrm{msec}$.

Open circles in $\mathrm{G}$ and $\mathrm{H}$ represent control state, filled circles during fentanyl effective state, (3-6 minutes after administration of $40 \mu \mathrm{g} / \mathrm{kg}$ ), and crosses during morphine effective state (3-6 minutes after administration of $5 \mathrm{mg} / \mathrm{kg}$ ).

Ordinates: amplitude of the monosynaptic reflex relative to the control size. Abscissac : conditioning-testing intervals in msec. 
$L_{i}$ ventral root at a supramaximal intensity for $\alpha$ fibers. This inhibition reached maximum at about $10 \mathrm{msec}$ and continued for about $50 \mathrm{msec}$ (Fig. $6 \mathrm{H}$ ). This time course was exactly the saine as previously reported by Renshaw (16). Neither fentanyl (40 $\mathrm{kg} / \mathrm{kg}$, crosses) nor morphine ( $5 \mathrm{mg} / \mathrm{kg}$, filled circles) induced any change in it.

D. Dorsal root potentials: In order to see the effects upon the presynaptic inhibitory mechanism which could possibly explain the observed MSR depression by the conditioning stimulation, effects of morphine, fentanyl upon the dorsal root potentials were investigated. The dorsal root potentials were recorded from $\mathrm{L}_{7}$ or $\mathrm{S}_{1}$ dorsal root filament upon stimulation of the quadriceps and the saphenous nerves at an intensity cither supramaximal or less than 2 times the nerve threshold. With a supramaximal shock to the muscle nerve dorsal root potentials with onset latency of about $5 \mathrm{mscc}$, peak time of about $40 \mathrm{msec}$ and duration of about $90-100 \mathrm{msec}$ were observed. With a supramaximal stimulation to the cutancous nerve, the dorsal root potentials of the similar time course were obtained. When the stimulus intensity was weakened (about 1.5 times of the nerve threshold of the muslce nerve fibers), the amplitude became smaller. Cord dorsum potentials were also recorded simultaneously. In these potentials evoked by stimuli of either intensitics, neither morphine $(5 \mathrm{mg} / \mathrm{kg})$ nor fentanyl $(40 / \mathrm{gg} / \mathrm{kg})$ produced any change. Although excitability of the terminals of cutaneous afferents, of low threshold and high (threshold), as well, was not examined, it seems that presynaptic mechanism is not involved so that the drug may influence the dorsal root potentials. Therefore, this would not be a primary cause for the observed MSR depression by the conditioning stimulation of these nerve fibers.

Effects of other narcotics upon the curaneous inhibition

From the results described above, it was shown that a small dose of both fentanyl and morphine blocked the late phase of the cutancous inhibition. Attempts were made to sce possible effects of other narcotic analgesics upon the cutaneous inhibition. It has been reported that dimethylthiambutene (17) has analgesic actions as potent as morphine and oxymorphone has that about 10 limes as potent as morphine (18). Intravenously administered oxymorphone $(0.25 \mathrm{mg} / \mathrm{kg})$ and dimethylthiambutene $(5 \mathrm{mg} / \mathrm{kg})$ were also found to block the late phase of the cutaneous inhibition similarly to fentanyl and morphine.

\section{DISCUSSION}

In the present experiments, such narcotic analgesics as morphine, fentanyl, dinethylthiambutene and oxymorphone showed a common characteristic effect at small doses of specifically blocking the late phase of the MSR inhibition from cutancous and muscular nerves. This portion of MSR inhibition is presumably due to an cxcitation of an Aô component of the cutaneous nerves and high threshold muscle afferents. It is considered that $\mathrm{C}$ component of the afferent fibers is not involved in the cutaneous inhibition described above, since it should take more than $100 \mathrm{msec}$ until the afferent volley of $\mathrm{C}$ fibers reach the entrance of the spinal cord, and the cutaneous inhibition described in this paper was observed over a period from about 5 to $30-35 \mathrm{msec}$ after the cutaneous 
nerve stimulation.

It is clear from the present results that these narcotic analgesics at small doses do not depress spinal interneurons generally but act specifically at some neurons activated directly or indirectly by such small fibers. As for the mode of action concerned in the abolishment of the MSR inhibition produced by these small fibers, there may be at least two possibilities; 1 ) spinal interneuronal chain activated by small fibers and having inhibitory influences to the mG-S motoncurons may be blocked by these narcotic analgesics, 2) spinal interncuronal chain activated by small fibers and having excitatory influences to $\mathrm{mG}-\mathrm{S}$ motoneurons may be facilitated by these drugs. However, there is no evidence available for selecting either one of these possiblities at present. In view of our present results, it is interesting that morphine reportedly inhibits activity of some dorsal horn cclls which are repetitively activated after a long delay by a single shock to dorsal roots at supramaximal intensity (21) and small doses of morphine and pethidine depress the nociceptive reflex discharges evoked by the stimulation of $A \delta$, post $\Lambda \dot{\delta}$ and $C$ fibers (7).

The blocking action of the late phase of the cutaneous inhibition by fentanyl was seen at a dose more than $0.8 / \mathrm{g} / \mathrm{kg}$ (sce Fig. 4) and the blockade by morphine was seen at a dose more than $0.5 \mathrm{mg} / \mathrm{kg}$. According to Janssen (9) fentanyl had analgesic action 100-300 times as potent as morphine in Haffner's method. This was confirmed by us, i.e., fentanyl is about 90 times as potent as morphine in Haffner's method in mice and about 300 times as potent in tooth pulp stimulation of chronic rabbit (22). In the present study, the minimal dose of fentanyl for the blockage of the late phase of the cutaneous inhibition was about 1/600 of that of morphine. The difference of the dose between morphine and fentanyl in this blocking action may be due to that of the sensitivity of neurons. The effective doses for this blocking action of other narcotic analgesics tested also ranged in their respective analgesic doses $(17,18)$. This quantitative accordance suggests that the underlying mechanism for the block of MSR inhibition may be in common with that for the analgesic action.

Jurna et al. (19) demonstrated that morphine and pethidine depressed the post-tetanic potentiation of the spinal monosynaptic reflex and also repetitive discharges of $\alpha$-motoneurons caused by stretching of extensor muscles (20) and suggested that these narcotic analgesics may act at presynaptic site. However, in our present experiments, the dorsal root potentials evoked by both weak and supramaximal stimulus intensity were not influenced and accordingly presynaptic mechanism at the primary afferent terminals appears uninfluenced by either fentanyl or morphine.

It was reported that morphine depressed the release of acetylcholine not only in isolated guinea pig ileum $(23,24)$ but also in the cat brain $(25-28)$. However, the recurrent inhibition via Renshaw cell arcs, relevant transmitter being considered as acetylcholine (29), was almost unchanged in our experiment by either morphine $(5 \mathrm{mg} / \mathrm{kg})$ or fentanyl $(40 \mu \mathrm{g} / \mathrm{kg})$. Kruglov $(8)$ previously demonstrated that the recurrent inhibition was little influenced by intravenous administration of morphine at a single dose of $5 \mathrm{mg} / \mathrm{kg}$, but it was gradually inhibited by adding the dose up to $15-20 \mathrm{mg} / \mathrm{kg}$. At a small dose $(0.5-5$ 
$\mathrm{mg} / \mathrm{kg}$ ) by which the late phase of the MSR inhibition from both Aò of cutaneous nerves and high threshold muscle afferents was blocked, the recurrent inhibition was uninfluenccd. From this, it appears that a small dose of morphine does not cause the reduction of the release of acetylcholine in lumbosacral spinal cord sufficient to influcnce the Renshaw inhibition. Therefore, a possibility that a cholinergic mechanism is involved in the late phase of the cutancous inhibition may be excluded.

\section{SUMMARY}

The effect of fentanyl and morphine upon the MSR depression induced by the low and high threshold cutaneous and musclar afferents in spinal cord were investigated in unanestherized low spinal cat. Morphine $(0.5-10 \mathrm{mg} / \mathrm{kg}$, i.v. $)$ and fentanyl $(0.8-80 \mu \mathrm{g} /$ $\mathrm{kg}$, i.v.) reduced the inhibition of the spinal monosynaptic reflex from the medial gastrocnemius-soleus nerve by a conditioning shock to Ao fibers of the cutaneous nerve and high threshold muscle afferents. While no significant influcnces were observed upon the MSR inhibitions from low threshold cutancous and muscle nerves, recurrent collaterals, and on the dosal root potentials.

Other narcotic analgesics tested, oxymorphone $(0.25 \mathrm{mg} / \mathrm{kg}$, i.v. $)$ and dimethylthiambutene ( $5 \mathrm{mg} / \mathrm{kg}$, i.v.), also depressed the MSR inhibition due to A $\delta$ fibers of the cutaneous nerve.

Acknowlcdgement: Authors thank Mr. S. Aoshima for his technical assistances through these experiments.

\section{REFERENCES}

1) Wikler, A.: J. Pharmac. exp. Ther. 80, 176 (1944)

2) Irwin, S., Houde, R.W., Benett, D.R., Hendershot, L.C. and Sefvers, M.H.: J. Pharmac, exp. Ther. 101, 132 (1951)

3) Wikler, A.: Pharmac. Rev. 2, 435 (1950)

4) Wikler, A., Surgeon, S. A.vd Frank, K.: J. Pharmac. exp. Ther. 94, 382 (1948)

5) Wiklir, A.: Proc. Soc. exp. Biol. Med. 58, 193 (1945)

6) MoClane, T.K. and Martin, W.R.: Int. J. Neuropharmac. 6, 89 (1967)

7) Koll, W., HaAsf, J., Biock, G. and Mïhlderg, B.: Int. J. Neuropharmac, 2, 57 (1963)

8) Krugrov, N.A.: Imt. J. Neuropharmac. 3, 197 (1964)

9) JANSSEN, P.A.: Arzneimittelforschlung 13, 502 (1963)

10) Gardocki, J.F. and Yelonsky, J.: Toxic. App. Pharmac. 6, 48 (1964)

11) Patton, H.D.: Nelrophysiology, Edited by Ruch, T.C. and Patton, H.D., Ed. 2nd, p. 181, W.B. Saunders Company, Philadelphia (1965)

12) Eccles, J.C.: The Principles of Neurophysiology, p. 314, Clarendon Press, Oxford (1953)

13) Patton, H.D.: Nelmophysiology, Edited by Ruch, T.C. And PAtton, H.D., Fd. 2nd, p. 73, W.B. Saunders Company, Philadelphia (1965)

14) Lloyd, D.P.C.: J. Neurophysiol. 4, 184 (1941)

15) Eccles, J.C., Eccles, R.M. and Lundberc, A.: J. Physiol. 138, 227 (1957)

16) Rensilaw, B.: J. Netrophysiol, 4, 167 (1941) 
17) Adamson, D.W. ANd Grlen, A.F.: Nafure, Lond. 165, 122 (1950)

18) Jaffe, J.H.: The Pharmacological Basis of Therupeutics, Ed. 3rd, p. 247, The Macmillan Company, New York (1965)

19) Jurna, I. A.id Schaefer, H.: Exporientia 21, 226 (1965)

20) Jur.va, I.: Int. J. Neuropharmac. 5, 117 (1966)

21) Tsou, K. And Chang, Z.L.: Acta physiol, sinica 27, 360 (1964), Cited in Lim, R.K.S.: Neuropharmacology of Pain and Analgesia, In procedings of the Third International Pharmacological Meeting. 9, Pharmacology of Pain, Edited by LIM, R.K.S., ARMStrong, D. ANd Pardo, E.G., p. 169 Pergamon Press, Oxford (1968)

22) Sakai, Y., Iwata, N., Mori, M. and Nishijma, Y.: Folia pharmac. jap. 67 (in press) (1971)

23) Schaumann, W.: Br. J. Pharmac. Chemother. 12, 115 (1957)

24) Patov, W.D.M.: Br. J. Pharmac. Chemother. 11, 119 (1957)

25) Beleslin, D. and Polak, R.L.: J. Physiol, 177, 411 (1965)

26) Beleslin, D., Polak, R.L. and Sproull, D.H.: J. Physiol. 177, 420 (1965)

27) Shaw, E.H. and BeNtlay, G.: Nature, Lond. 169, 712 (1952)

28) Crossland, J. and Slater, P.: Br. J. Phurmac. Chemother. 33, 42 (1968)

29) Ecclfs, J.C., Fatt, P. ANd Konetsu, K,: J. Physiol. 126, 524 (1954) 